\title{
Medical Factors Influencing Protein Energy Malnutrition in Children Under Five Years Old at Kenyatta National Hospital, Kenya
}

\author{
Sherry Oluchina \\ School of Nursing, Jomo Kenyatta University of Agriculture and Technology, Nairobi, Kenya
}

\section{Email address:}

oluchinasherry@yahoo.com

\section{To cite this article:}

Sherry Oluchina. Medical Factors Influencing Protein Energy Malnutrition in Children Under Five Years Old at Kenyatta National Hospital, Kenya. International Journal of Clinical and Developmental Anatomy. Vol. 3, No. 1, 2017, pp. 1-4. doi: 10.11648/j.ijcda.20170301.11

Received: July 21, 2016; Accepted: July 30, 2016; Published: April 13, 2017

\begin{abstract}
Introduction: Protein energy malnutrition (PEM) results from deficiency of proteins and energy. Objective: This study sought to determine the influence of medical factors on PEM in children below five years old at KNH. Method: 118 children under five years old plus their biological mothers participated in this cross-sectional quantitative study. Questionnaires were administered to the biological mothers of the children and anthropometric measurements were taken from the children. Multi-stage sampling was used to select eligible children plus their biological mothers. Analysis of data was done using SPSS version 16. Results: The prevalence of underweight was $59.3 \%$, stunting $53.3 \%$ and wasting $33.9 \%$ among children aged 0 to 59 months in KNH. Medical factors that predisposed to PEM were: illness, immunization status, dietary care during illness time and health seeking behavior. Conclusion: Medical factors greatly influenced nutritional status of children under five years old. Recommendations: Health education should be enhanced in the hospital settings on importance of seeking medical care in case of an illness and importance of adequate feeding of the child during illness.
\end{abstract}

Keywords: Protein Energy Malnutrition, Stunting, Wasting, Underweight

\section{Introduction}

Protein energy malnutrition (PEM) was the most common form of malnutrition resulting from deficiency of proteins and energy. The clinical conditions that occurred included: underweight, marasmus, kwashiokor and marasmickwashiokor. More recent nutrition surveys used 'wasting' and 'stunting' in defining PEM. Wasting was a feature of acute PEM, whereas stunting was a result of long standing under nutrition. In underweight child one or another of these may be noticeable (Stanfield, Balldin, \& Versluys, 2009).

The percentage of stunted, wasted, and underweight children did not change substantially in Kenya between 1993 and 2003 (Kenya Demographic and Health Survey (KDHS), 2014 \& World Health Organization (WHO), 2003). The percentage of children below five years of age who were wasted was $7.8 \%$ in $1993,6.1 \%$ in 1998 , and $4.8 \%$ in 2003 . The percentage of those who were stunted was $33.6 \%, 33 \%$ and $30.6 \%$ in 1993, 1998, and 2003 respectively (United Nation Children Fund, 2006). The prevalence of PEM in the developing countries was $40 \%$ while in the developed countries it ranged from 2 to $10 \%$. In many parts of Africa, the prevalence of PEM in children under five years old was an average of $40 \%$. In East Africa the level of stunting was over 44\% (Stanfield, et al. 2009). In Kenya, nearly a half of the children less than five years were unable to grow to their full physical and mental potential owing to protein energy malnutrition. This was as a result of more complex medical factors that affect the child's nutritional status (KDHS, 2014).

A study of children admitted in Kenyatta National Hospital (KNH) in Kenya, found prevalence of PEM among children less than 5 years to be $75 \%$ at admission. Approximately $50 \%$ of one thousand deaths that occurred each year in children under five-years-old in $\mathrm{KNH}$ were directly or indirectly attributed to PEM according to 2006 statistics (Nyandiko, 2010). Despite all these, no study had been done to detect how medical factors influenced development of PEM in children under five years old in KNH. 


\section{Materials and Methods}

\subsection{Study Design, Setting and Population}

The study was a cross-sectional quantitative study carried out in medical paediatric wards, maternal and child health clinic and paediatrics outpatient clinic of $\mathrm{KNH}$, Kenya. KNH is the largest referral hospital in Kenya. The study population comprised of children aged below 60 months in the above departments in KNH plus their biological mothers.

\subsection{Sample Selection and Sample Size}

Multi-stage sampling was used in selection of eligible children and their biological mothers. A total number of 118 children under five years old plus their biological mothers formed the sample size which was obtained using the Fisher's formula. Only the under five years old children who fulfilled the following inclusion criteria were recruited in the study:

1. Children aged below 60 months.

2. Children who were admitted in medical paediatric ward, attending maternal and child health clinic or paediatric outpatient clinic of $\mathrm{KNH}$.

3. Children whose mothers gave consent.

4. Children without chronic diseases, malignancies, or any physical or mental conditions.

\subsection{Data Collection}

Data was collected using questionnaire and anthropometric assessment devices (portable hanging scales were used to weigh and wooden length/height boards were used to take length/height of the children).

\subsection{Pre-test of Tool}

Pilot study was done using children whose ages were below five years plus their biological mothers who were admitted in medical paediatric ward at Mbagati district Hospital in Nairobi, Kenya.

\subsection{Data Analysis and Presentation of Findings}

Data was analyzed using SPSS version 16. Anthropometric statistical programme was employed to convert raw anthropometric data into anthropometric indices and then these were compared with that of National centre Health statistics (NCHS) reference figures. Chi-squarewas used to test the significance of the relationship between independent and dependent variables that were categorical in nature. Logistic regression was used to predict relationship between variables. Presentation of descriptive data was done in the form of descriptive statistics, frequency distributions tables and graphic forms.

\subsection{Ethical Consideration}

Approval was sought from $\mathrm{KNH}$ ethical and research committee. Authority was sought from $\mathrm{KNH}$ administrators. Consents were given by the child's mother.

\section{Results}

\subsection{Morbidity}

Mothers reported that more than 96\% (114) of their children had suffered an illness two weeks prior to the study. Majority of the children $60.5 \%$ (69) had suffered gastrointestinal infections (Figure 1). The study also established that $16.9 \%$ (20) of index children suffered from one or more chronic illnesses (asthma, epilepsy, and diabetes mellitus).

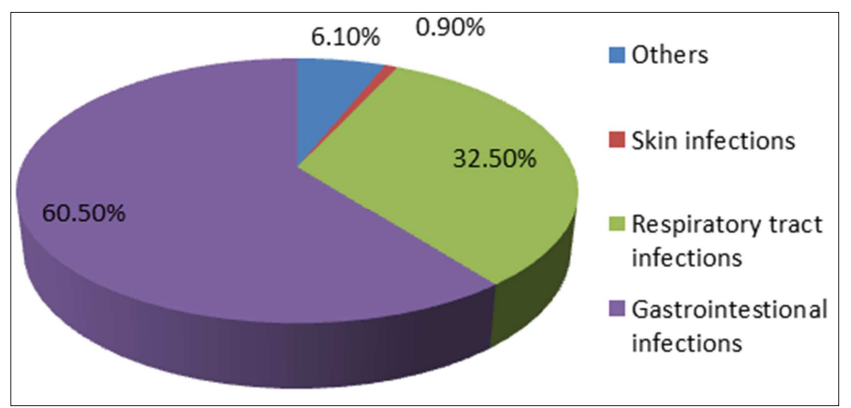

Figure 1. Distribution of illnesses that index children suffered.

There was higher proportion of underweight and stunted children, $60 \%$ and $58 \%$ respectively, in children who were reported suffering from childhood morbidity. The proportion of underweight children was higher $60 \%$, among those suffering from chronic illnesses. However, there was no statistically significance relationship between childhood morbidity and PEM in under five years old children $(\mathrm{p}>0.05)$ (Table 1$)$.

Table 1. Bi-variate analysis of childhood morbidity and PEM.

\begin{tabular}{|c|c|c|c|c|c|c|c|c|c|c|c|c|}
\hline & \multicolumn{4}{|c|}{ Weight-for-age } & \multicolumn{4}{|c|}{ Height-for-age } & \multicolumn{4}{|c|}{ Weight-for-height } \\
\hline & $\begin{array}{l}\text { Normaln } \\
(\%)\end{array}$ & $\begin{array}{l}\text { Under Weightn } \\
(\%)\end{array}$ & Chi & PValue & $\begin{array}{l}\text { Normaln } \\
(\%)\end{array}$ & $\begin{array}{l}\text { Stuntedn } \\
(\%)\end{array}$ & Chi & Pvalue & $\begin{array}{l}\text { Normaln } \\
(\%)\end{array}$ & $\begin{array}{l}\text { Wastedn } \\
(\%)\end{array}$ & Chi & PValue \\
\hline \multicolumn{13}{|l|}{ Morbidity } \\
\hline Yes & $46(40)$ & $68(60)$ & \multirow{2}{*}{0.02} & \multirow{2}{*}{0.9} & $44(42)$ & $60(58)$ & \multirow{2}{*}{0.03} & \multirow{2}{*}{0.86} & $73(66)$ & $38(34)$ & \multirow{2}{*}{0.01} & \multirow{2}{*}{0.91} \\
\hline No & $2(50)$ & $2(50)$ & & & $1(25)$ & $3(75)$ & & & $2(50)$ & $2(50)$ & & \\
\hline Diarrhea/vomiting & $28(41)$ & $41(59)$ & \multirow{2}{*}{0.004} & \multirow{2}{*}{0.95} & $24(38)$ & $39(62)$ & \multirow{2}{*}{1.16} & \multirow{2}{*}{0.28} & $44(65)$ & $24(35)$ & \multirow{2}{*}{0.09} & \multirow{2}{*}{0.77} \\
\hline Others & $18(40)$ & $27(60)$ & & & $20(49)$ & $21(51)$ & & & $29(67)$ & $14(33)$ & & \\
\hline \multicolumn{13}{|l|}{ Chronic illness } \\
\hline Yes & $8(40)$ & $12(60)$ & \multirow{2}{*}{0.01} & \multirow{2}{*}{0.94} & $9(50)$ & $9(50)$ & \multirow{2}{*}{0.62} & \multirow{2}{*}{0.43} & $11(55)$ & $9(45)$ & \multirow{2}{*}{1.11} & \multirow{2}{*}{0.29} \\
\hline No & $40(41)$ & $58(59)$ & & & $36(40)$ & $54(60)$ & & & $64(67)$ & $31(33)$ & & \\
\hline
\end{tabular}




\subsection{Health Seeking Behavior}

$2.5 \%$ (3) of children who suffered the above illness stayed at home during the first week of the illness; $0.8 \%$ (1) used herbs first before seeking medical advice; 7.6\% (9) bought over the counter drugs and tried to use before seeking medical advice and $89 \%$ (105) took their children to health facilities.

Most respondents $48.3 \%$ (57) reported that they sought health care from dispensaries; $25.4 \%$ (30) health centers;
$21.2 \%$ district, provincial and national hospitals and 5\% (6) local pharmacies.

Higher proportions of children, $60 \%$ and $58 \%$, whose mothers reported they sought medical attention were underweight and stunted respectively. However, highest proportions $(67 \%)$ of stunted children were seen in those whose mothers reported they did not seek medical attention, but stayed at home during the first week of illness. However, all these were statistically insignificant $(\mathrm{p}>0.05)$ (Table 2).

Table 2. Bi-variate analysis of health seeking behavior and PEM.

\begin{tabular}{|c|c|c|c|c|c|c|c|c|c|c|c|c|}
\hline & \multicolumn{4}{|c|}{ Weight-for-age } & \multicolumn{4}{|c|}{ Height-for-age } & \multicolumn{4}{|c|}{ Weight-for-height } \\
\hline & $\begin{array}{l}\text { Normaln } \\
(\%)\end{array}$ & $\begin{array}{l}\text { Under } \\
\text { Weightn (\%) }\end{array}$ & Chi & PValue & $\begin{array}{l}\text { Normaln } \\
(\%)\end{array}$ & $\begin{array}{l}\text { Stuntedn } \\
(\%)\end{array}$ & Chi & Pvalue & $\begin{array}{l}\text { Normaln } \\
(\%)\end{array}$ & $\begin{array}{l}\text { Wastedn } \\
(\%)\end{array}$ & Chi & PValue \\
\hline $\begin{array}{l}\text { Stayed home } \\
\text { medical assistance }\end{array}$ & $\begin{array}{l}2(67) \\
46(40)\end{array}$ & $\begin{array}{l}1(33) \\
69(60)\end{array}$ & 0.11 & 0.74 & $\begin{array}{l}1(33) \\
44(42)\end{array}$ & $\begin{array}{l}2(67) \\
61(58)\end{array}$ & 0.09 & 0.77 & $\begin{array}{l}2(67) \\
73(65)\end{array}$ & $\begin{array}{l}1(33) \\
39(35)\end{array}$ & 0.31 & 0.58 \\
\hline
\end{tabular}

\subsection{Immunization Status}

Majority of respondents $90.7 \%$ (107) reported that their children were fully immunized for age. Of those whose children were not fully immunized for age, $90.9 \%$ (10) gave the reason of why they were not fully immunized for age as, the children were sick. The remainder $9.1 \%$ (1) said, the clinic was too far and they had no money for "matatu" fare.

Sixty six point nine percent (79) of the respondents reported that, they still took their children to Maternal and Child Health Clinic (MCH) for the routine services, despite them completing all Kenya Expanded Program of immunization (KEPI) vaccinations. Of those who had stopped, $46.2 \%$ (18) reported to have stopped when their children were 8 -9 months, while $51.3 \%$ (20) when their children were greater than 9 months in age.

Among those who were fully immunized for age, there was higher proportion $(61 \%)$ of underweight children. Sixty nine percent of children whose mothers reported they had stopped taking them to $\mathrm{MCH}$ were stunted. Higher proportion of children $(72 \%$ and $75 \%$ ) who stopped being taken to MCH between 8 and 9 months were underweight and stunted respectively. Despite this, none of these was statistically significant with PEM. ( $\mathrm{P}>0.05)$ (Table 3$)$.

Table 3. Bi-variate analysis of childhood immunization and PEM.

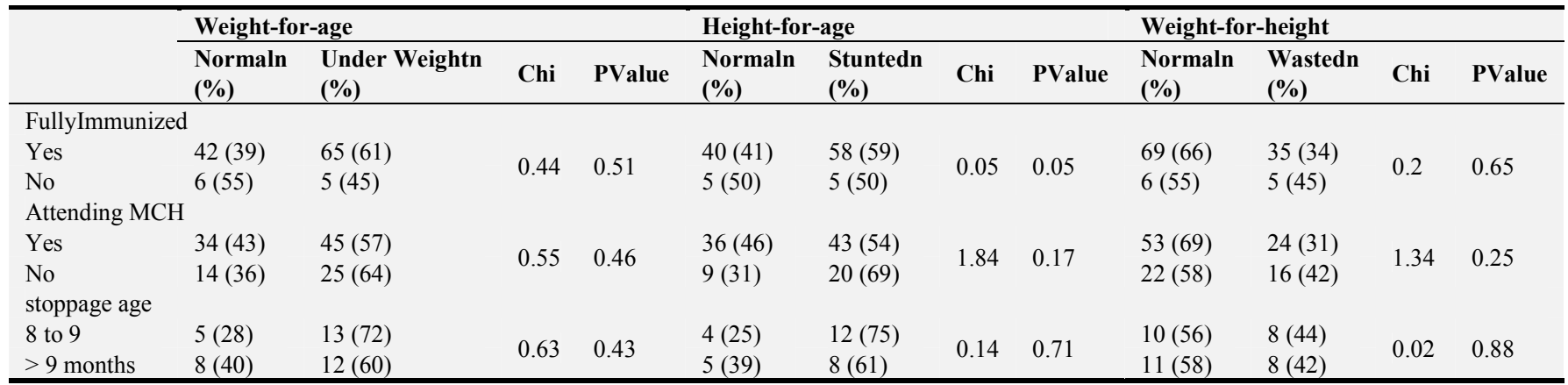

\subsection{Dietary Care During Illness}

Most mothers $84.7 \%$ (83) reported that their children fed less times during illness, $2 \%$ (2) more times than usual; $10.2 \%$ (10) as usual and $3.1 \%$ (3) fed on special food. Over $96 \%$ (75) of mothers who were breastfeeding, continued breastfeeding during diarrhea episodes, $79.6 \%$ (78) continued feeding them with other foods other than breast milk and $41.8 \%$ (41) gave them special foods. The foods considered special included fruits, mala, special uji (uji with milk, groundnuts, and margarine), yoghurt and oral rehydration salt (ORS). 30\% (29) of the mothers were for the opinion that some types of foods should not be given to children during illness for various reasons as shown below (Table 4).
Table 4. Type of food or fluid and reasons for not giving the child during illness.

\begin{tabular}{ll}
\hline Type of food or fluid & Reason \\
\hline Meat & Has a lot of cholesterol. \\
Mixture of beans and maize & Culturally was not child food \\
Plain beans or maize & Are hard for chewing and child has \\
Beverages & less strength. \\
Alcohol & Has a lot of acid. \\
\hline
\end{tabular}

\section{Discussion}

The most common illnesses reported were gastrointestinal infections $(60.5 \%)$ and respiratory tract infections (32.5\%). 
These illnesses were among the major childhood illnesses in Kenya (KDHS, 2014). Similar childhood illnesses had also been reported in a study done in Kibera slum, Nairobi (Ibtisam, 2008). This was so, because majority of respondents $(92 \%)$, were living in slum and semi slum regions in Nairobi, where the state of living was poor, increasing their chances of getting gastrointestinal and respiratory diseases.

Although there was no statistical significance between childhood illnesses and PEM, the prevalence of stunted and underweight children was higher among sick children. This was because, childhood morbidity increases body metabolism against stresses and lowers child's appetite, and these reduces nutrients within the body. These findings were similar to the study done in Kibera slum, Nairobi (Ibtisam, 2008).

Majority ( $89 \%$ ) of respondents took their children to health facilities during the $1^{\text {st }}$ week of illness. These findings concurred with that of a study done in Siaya district, Kenya, where it was found that most sick children sought medical assistance in health facilities (Ayaya, et al., 2010). It was surprising that the rate of underweight and stunted children was higher among children who were taken to health facilities. This was contributed to the fact that PEM was caused by other factors. These findings were in contrast to the findings of the above study.

The current study depicted a high percentage of immunization $(90.7 \%)$ than the reported National rate of $57 \%$ (KDHS, 2014). This was due to immunization campaigns which were on going in the country. More than a half of respondents stopped taking children to $\mathrm{MCH}$ after 9 months, because they had completed the KEPI vaccinations. Same statistics had also been reported by KDHS, 2014.

The proportion of underweight children was higher among children who were fully immunized for age and this was attributed to factors like feeding practices and childhood morbidity. But the proportion of underweight and stunted children was higher among children who stopped being taken to $\mathrm{MCH}$ between 8 and 9 months, because they lacked essential KEPI services which were essential for their health that continued after 8 or 9 months. The first and second findings were in contrast and similar with studies done in Siaya district, Kenya and Moi Teaching and Referral Hospital (MTRH), Kenya, respectively, which showed low prevalence of PEM among children who were fully immunized for age and those who attended MCH after 9 months (Musomi, 2008 and Ayaya, Esamal, Rotich, \& Olwambula 2010).

Study findings that most mothers feed their children less times during illness, contrasted recommendation of health workers advocating for increased feeding of children when they were sick. Sick children required small frequent meals, since infections affected their appetite and interfered with their gastrointestinal motility (Tomkins \& Watson, 2011)). Majority of mothers continued breastfeeding and feeding their children on complementary feeds during diarrhea, which was important. These findings were similar to of Kibera slum in Kenya (Ibtisam, 2008).

The number of feeding during illness and wasting was statistically significant $(\mathrm{p}=0.009)$. The probability of a child who was feed on less feeds than normal during illness becoming wasted was a third. During illness, the body metabolic rate increases and it uses stored nutrients causing wasting. These findings were in contrast with a study done Kibera that showed no statistical significance (Ibtisam, 2008).

\section{Conclusions}

Among the medical factors influencing PEM, dietary care during illness was statistically significant with PEM. Wasting was significantly associated with the times of feeding during illness $(p=0.009)(p<0.05)$. It was important that under-five children were fed well during illnesses, since most of their stored nutrients were utilized during the stress period.

\section{Recommendations}

Health education should be enhanced in the hospital settings on importance of seeking medical care in case of an illness and importance of adequate feeding of the child during illness.

\section{References}

[1] Ayaya, S. O, Esamal, F. O, Rotich, J \& Olwambula, A. R (2010). Socio-economic factors predisposing under five years old to severe protein energy malnutrition at Moi Teaching and Referral Hospital, Eldoret, Kenya, East Africa Medical Journal, 81 (8), 415-422.

[2] Benn, H. (2012). DFID'S Bid to break child poverty cycle. Water and sanitation update, East Africa Medical Journal, 9 (2), 14.

[3] Ibtisam, A. E. (2008). Prevalence of malnutrition and some associated factors on child's nutritional status in an urban slum, Kibera, Nairobi, Kenya, Msc, Thesis; Applied Nutrition programme, University of Nairobi.

[4] Kenya Demographic and Health Survey. (2014). Republic of Kenya, National council for population and development, Central Bureau of statistics.

[5] Musomi, M. (2008). Nutritional status of children in Usigu division, of Siaya district, Kenya, Msc, Thesis, Applied Nutrition program, University of Nairobi.

[6] Nyandiko, M. (2010). Deteriorating nutritional status of patients admitted in $\mathrm{KNH}$ : Magnitude and consequences, MMed thesis, University of Nairobi.

[7] Stanfield. P. Balldin, B. \& Versluys, Z (2009). Child health, $2^{\text {nd }}$ edition, Published by the African medical and research foundation (AMREF), Wilson Airport. Nairobi. Kenya.

[8] Tomkins, A \& Watson, F. (2011). Malnutrition and infections, A review of infection-malnutrition cycle, USAID.

[9] United Nation Children Fund. (2006). The state of the world children, Oxford University Press.

[10] World Health Organization. (2003). Health systems: Improving performance., Oxford University Press. 